\title{
Decreased cortical thickness, as estimated by a newly developed ultrasound device, as a risk for vertebral fracture in type 2 diabetes mellitus patients with eGFR of less than $60 \mathrm{~mL} / \mathrm{min} / 1.73 \mathrm{~m}^{2}$
}

\author{
T. Mishima $\cdot$ K. Motoyama $\cdot$ Y. Imanishi • \\ K. Hamamoto $\cdot$ Y. Nagata $\cdot$ S. Yamada $\cdot$ N. Kuriyama $\cdot$ \\ Y. Watanabe $\cdot$ M. Emoto $\cdot$ M. Inaba
}

Received: 16 January 2014 / Accepted: 5 August 2014 / Published online: 4 September 2014

(C) The Author(s) 2014. This article is published with open access at Springerlink.com

\begin{abstract}
Summary Cortical porosity is increasingly recognized as an important risk for fracture in DM patients. The present study demonstrated that decreased cortical thickness, assessed using a newly developed quantitative ultrasonic bone densitometry, is a significant risk factor for vertebral fractures in type 2 diabetes mellitus patients with stage 3 or higher chronic kidney disease, but not in those without.

Introduction Cortical porosity is increasingly recognized as an important risk factor for fracture in type 2 diabetes mellitus (T2DM) patients as well as in stage 3 chronic kidney disease (CKD) patients in whom serum parathyroid hormone (PTH) starts to increase. The present study aimed to clarify whether the coexistence of CKD might affect the relationship of decreased cortical thickness (CoTh) in the development of vertebral fractures (VF) in T2DM patients.

Methods In this cross-sectional study, trabecular bone mineral density (TrBMD), elastic modulus of trabecular bone (EMTb), and CoTh were estimated with a new quantitative ultrasound bone densitometry in $173 \mathrm{~T} 2 \mathrm{DM}$ patients. VFs were identified radiographically.
\end{abstract}

Electronic supplementary material The online version of this article (doi:10.1007/s00198-014-2843-x) contains supplementary material, which is available to authorized users.

T. Mishima $\cdot \mathrm{K}$. Motoyama $(\bowtie) \cdot \mathrm{Y}$. Imanishi $\cdot \mathrm{K}$. Hamamoto $\cdot$ Y. Nagata $\cdot$ S. Yamada $\cdot$ M. Emoto $\cdot$ M. Inaba

Department of Metabolism, Endocrinology, and Molecular

Medicine, Graduate School of Medicine, Osaka City University,

1-4-3, Asahi-machi, Abeno-ku, Osaka 545-8585, Japan

e-mail: m1399776@med.osaka-cu.ac.jp

N. Kuriyama $\cdot$ Y. Watanabe

Department of Epidemiology for Community Health and Medicine,

Kyoto Prefectural University of Medicine, Kyoto, Japan
Results Thirty-nine patients (22.5\%) had VF. Those with estimated glomerular filtration rate (eGFR) $<60 \mathrm{~mL} / \mathrm{min} / 1.73 \mathrm{~m}^{2}$ (low eGFR) showed a significantly higher VF rate (32.4 \%) than those with eGFR $\geq 60 \mathrm{~mL} / \mathrm{min} / 1.73 \mathrm{~m}^{2}$ (high eGFR, $16.2 \%$ ). Serum PTH was significantly higher with low eGFR than with high eGFR. In those with high eGFR, EMTb was significantly lower in $\mathrm{VF}(+)$ than $\mathrm{VF}(-)$. In those with low eGFR, TrBMD, $\mathrm{EMTb}$, and CoTh were significantly lower in $\mathrm{VF}(+)$ than in $\mathrm{VF}(-)$. In a multivariate logistic regression analysis, EMTb was independently and significantly associated with VF in T2DM patients with a high eGFR, in contrast to those with only CoTh with VF in T2DM with low eGFR.

Conclusion This study demonstrated CoTh as a factor independently associated with VF in T2DM patients with low eGFR and increasing serum PTH levels.

Keywords Bone fracture $\cdot$ Bone mineral density $\cdot$ Chronic kidney disease $\cdot$ Cortical thickness $\cdot$ Type 2 diabetes

\section{Introduction}

It is increasingly recognized that patients with diabetes mellitus (DM) are at higher risk of bone fracture relative to their bone mineral density (BMD) $[1,2]$. A number of reports, including ours [3], indicate a higher prevalence of vertebral fracture (VF) in those with type 2 DM (T2DM) than in those without, irrespective of the insignificant difference in BMD between patients with or without T2DM [4]. Meta-analysis studies recently reported that T2DM patients exhibited a higher fracture rate, particularly in appendicular bones, despite their comparable BMD [5, 6], suggesting the possible involvement of impaired bone quality, but not BMD, in the development of bone fragility $[7,8]$. It is increasingly recognized that 
the higher fracture rate in T2DM patients is explained by increased cortical porosity, as shown by high-resolution peripheral quantitative computed tomography (HR-pQCT) [9]. We have recently reported validation of a newly developed quantitative ultrasound (QUS) device, the LD-100 system (Oyo Electric, Kyoto, Japan); this system can estimate both trabecular and cortical bone components [10,11], as illustrated by a significant correlation of bone parameters estimated by the new QUS with the respective parameters as measured by Stratec pQCT [12].

It has been recently recognized that serum parathyroid hormone (PTH) plays an important role in the development of cortical porosity, which starts to increase in chronic kidney disease (CKD) patients as they progress to stage $3[13,14]$, for whom evidence shows a higher fracture rate at the femur neck [15-18]. Since T2DM patients are complicated with stage 3 CKD more often than non-DM patients, it is important to examine whether DM by itself or in association with CKD might be a more important contributing factor to the development of cortical porosity.

Therefore, the present study aimed to determine (i) trabecular and cortical bone components in T2DM patients using the new QUS device and (ii) to determine the involvement of CKD complications in the development of decreased cortical thickness in T2DM patients.

\section{Subjects and methods}

\section{Subjects}

A total of 173 Japanese T2DM patients (98 men and 75 women) admitted to the Diabetes Center at Osaka City University Hospital were enrolled consecutively in the study. Written informed consent was obtained from all patients prior to participation. This cross-sectional study was approved by the Ethics Review Committee of Osaka City University Graduate School of Medicine (no. 164).

Patients diagnosed as T2DM according to Japan Diabetes Society (JDS) criteria were on either dietary therapy only, oral agents (30\% sulfonylurea, $35 \%$ dipeptidyl peptidase- 4 inhibitor, $2.1 \%$ glinide, $32.1 \%$ metformin, $5.7 \%$ thiazolidinedione, or $7.1 \%$ glucagon-like peptide-1 agonist), or insulin (39\%) for glycemic control. Mean values for age and estimated glomerular filtration rate (eGFR) were $62.3 \pm$ 12.2 years and $64.2 \pm 25.2 \mathrm{~mL} / \mathrm{min} / 1.73 \mathrm{~m}^{2}$, respectively.

All patients were free of significant acute illness or malignancy. Patients with severe renal failure such as stage $5 \mathrm{CKD}$ and abnormal calcium metabolism such as primary hyperparathyroidism or a history of falls or traffic accidents were excluded to eliminate the possibility of injury-associated fractures. To avoid confounding results due to the treatment, patients who had a history of taking any drugs or hormones that affect bone metabolism, such as corticosteroids, warfarin, anti-osteoporotic drugs such as bisphosphonates, PTH (1-34), vitamin $\mathrm{D}$ derivatives, estrogen and selective estrogen receptor modulators, supplementary calcium, phosphate binders, or thyroid hormone, were excluded from the present study.

\section{Biochemical parameters}

Venous blood samples were obtained in the morning after an overnight fast. Fasting plasma glucose (FPG) was measured by the enzymatic method using an autoanalyzer in the hospital (GA-1171; ARKRAY, Inc., Kyoto, Japan), and glycated hemoglobin $(\mathrm{HbAlc})$ was measured using high-performance liquid chromatography (HA-8180; ARKRAY, Inc., Kyoto, Japan). Calcium $(\mathrm{Ca})$, phosphate $(\mathrm{P})$, and creatinine $(\mathrm{Cr})$ were measured by enzymatic methods using an autoanalyzer in the hospital (BM6070; JEOL Ltd., Tokyo, Japan). Measurement of serum PTH levels was performed simultaneously to avoid inter-assay variance. Serum active PTH (1-84) levels were measured using the whole PTH assay (LSI Medience Co., Tokyo, Japan) with a two-site IRMA assay as described previously [19]. Serum 1,25-dihydroxyvitamin D $\left(1,25(\mathrm{OH})_{2} \mathrm{D}\right)$ was determined by radioimmunoassay (LSI Medience Co., Tokyo, Japan). Tartrate-resistant acid phosphatase-5b (TRACP-5b) activity was measured by using the enzyme-linked immunoassay (novel fragment absorbed immunocapture enzymatic assay [FAICEA]) method using two monoclonal antibodies (BML, Inc., Tokyo, Japan). Serum bone alkaline phosphatase (BAP) and intact osteocalcin $(\mathrm{OC})$ were measured with an enzyme immunoassay. To assess renal function, eGFR was calculated using the equation proposed by the Japanese Society of Nephrology [20]: eGFR $\left(\mathrm{mL} / \mathrm{min} / 1.73 \mathrm{~m}^{2}\right)=175 \times$ serum creatinine $\mathrm{e}^{-1.154} \times$ age $^{-0.203}$. For women, this value was multiplied by 0.742 . HOMA-IR was calculated from the FPG and serum insulin as follows: HOMA-IR $=($ FPG $[\mathrm{mg} / \mathrm{dL}]) \times($ fasting insulin $[\mu \mathrm{U} / \mathrm{mL}]) / 405[21]$.

\section{Bone densitometry}

Ultrasonic measurements were performed on the nondominant, ultradistal radius using the new QUS device, allowing estimation of trabecular BMD (TrBMD) of the radius, elastic modulus of the trabecular component (EMTb), and cortical thickness (CoTh) [12, 22, 23]. Validation of TrBMD and CoTh estimated by the new QUS device was done by demonstrating a significant correlation with values measured by Stratec pQCT [12]. Breban reported reproducibility values of $4.8,10.3$, and $3.5 \%$ for TrBMD, EMTb, and CoTh, respectively [10].

As reported previously, the new QUS device consists of two ultrasonic transducers, located coaxially in the forward direction and it is equipped with a computer system. The transducers move simultaneously for scanning: one transmits 
ultrasound through the objective region and the other receives ultrasonic signals. TrBMD, which is estimated by quantifying attenuation of ultrasound waves transmitted through the bone [22], is expressed in milligrams per cubic centimeter. In the field of structural physics in particular, it has been established that the EMTb (structural elasticity) can be quantified by the transmission velocity of the fast wave propagated through the trabecular bone structures [11, 24]; values are expressed in gigapascal (GPa). The new QUS device can also estimate CoTh by analyzing the reflected and transmitted ultrasonic signals as previously described [23, 25]. A pair of broadband ultrasonic transducers are faced and coaxially aligned in the water. The distance between the two transducers (distance A) and the ultrasonic signal level is checked automatically by the transmission mode through the water as a reference medium.

As shown in Supplemental Fig. 1, the total radial thickness (distance B) is estimated by the echo measurements of both transducers; that is, both transducers are used to measure each distance between the transducer surface and the cortical bone surface by the echo method. The total radial thickness (distance B) is estimated by subtracting the distances of the transducer and the cortical surface of both sides (distance $\mathrm{C} 1+\mathrm{C} 2$ ) from the distance between the two transducers (distance A). The total radial thickness can be expressed as $\mathrm{B}=\mathrm{A}-(\mathrm{C} 1+\mathrm{C} 2)$ (Supplemental Fig. 1a). It is not possible to apply the echo measurements to cortical thickness. The inner boundary of cortical bone is connected to the trabecular network through a rough, random, and arbitrary boundary layer. Incident ultrasound is scattered in the boundary region. The backscattered ultrasound or the reflected signal to the transducer cannot be used to measure cortical thickness because of considerable waveform deformation and amplitude reduction.

The new QUS device measures the fast and slow waves, transmitted through trabecular bone, to estimate bone parameters. The propagation speed of the fast wave and the amplitudes of both the fast and the slow waves depend on the trabecular bone state, whereas the propagation speed of the slow wave is always constant, independent of trabecular bone density. The propagation speed of the slow wave corresponds to that of the bone marrow.

CoTh (the sum of cortical bone thicknesses on the input and output sides of the ultrasonic wave) is estimated by the total radial thickness, and its propagation time is measured by the slow wave at nominal propagation speeds in the bone marrow $(1,400 \mathrm{~m} / \mathrm{s})$ and in cortical bone $(3,300 \mathrm{~m} / \mathrm{s}$; Supplemental Fig. 1b).

The validity of estimates was confirmed by comparing with measurements from pQCT; the new QUS system has been approved as medical equipment in Japan. CoTh is expressed in millimeters.

\section{Assessment of fractures}

In all subjects, VFs were identified on lateral and anteriorposterior X-ray films of the thoracic and lumbar spine according to the semiquantitative method by two investigators who were blinded to the other's readings. VFs were defined as grades 1-3 according to the classification advocated by Genant HK et al. [26]. When the grade was different between the two investigators, they were advised to reevaluate X-ray findings. When the result was still different, the milder grade was used.

Statistical analysis

All data were analyzed with the Stat View 5.0J program. Numerical parameters with normal distribution are shown as mean $\pm \mathrm{SD}$, and those with non-normal distribution are expressed as median with interquartile range (IQR). The difference between T2DM patients with and without VFs was analyzed by Student's $t$ test or the Mann-Whitney $U$ test. Chi-square tests were used to compare fractures between men and women. Multivariate logistic regression analysis was performed to estimate the independent risk of VF. Odds ratios (ORs) and $95 \%$ confidence intervals (95\% CIs) were collectively calculated. $p<0.05$ was defined as statistically significant.

\section{Results}

Clinical characteristics of enrolled patients

The baseline characteristics of the enrolled subjects are shown in Table 1. Age and duration of T2DM were 62.3 and 13.0 years, respectively, with a BMI of $26.1 \mathrm{~kg} / \mathrm{m}^{2}$. Parameters for glycemic control, such as FPG and HbA1c, were above their respective normal upper limits. The parameter for insulin resistance, HOMA-R, was well above the normal upper limit.

Serum Cr was $0.84(0.64-1.04) \mathrm{mg} / \mathrm{dL}$, and eGFR was suppressed to $64.2 \pm 25.2 \mathrm{~mL} / \mathrm{min} / 1.73 \mathrm{~m}^{2}$. Serum Ca, phosphate, and whole PTH levels were all within their respective normal ranges. Other serum parameters for $\mathrm{Ca}$ metabolism, such as $1,25(\mathrm{OH})_{2} \mathrm{D}$, TRACP-5b, and BAP, were all within their respective normal range; in contrast, serum intact $\mathrm{OC}$ was significantly reduced to $3.1 \mathrm{ng} / \mathrm{mL}$. Among $173 \mathrm{~T} 2 \mathrm{DM}$ patients, 39 patients $(22.5 \%)$ had X-ray findings, indicating prevalent VF on a lateral view of the vertebrae.

Comparison of clinical parameters between T2DM patients with and without VF

As shown in Table 2, the $\mathrm{VF}(+)$ group had a significantly greater age and duration of $\mathrm{T} 2 \mathrm{DM}$ than the $\mathrm{VF}(-)$ group. There was no 
Table 1 Clinical profiles of 173 T2DM patients

\begin{tabular}{ll}
\hline Clinical variables & \\
\hline$N$ (men/women) & $173(98 / 75)$ \\
Age (year) & $62.3 \pm 12.2$ \\
Duration of T2DM (year) & $13.0(5.5-20.5)$ \\
BMI $\left(\mathrm{kg} / \mathrm{m}^{2}\right)$ & $26.1 \pm 5.5$ \\
$\mathrm{Cr}(\mathrm{mg} / \mathrm{dL})$ & $0.84(0.64-1.04)$ \\
eGFR $\left(\mathrm{mL} / \mathrm{min} / 1.73 \mathrm{~m}^{2}\right.$ & $64.2 \pm 25.2$ \\
FPG $(\mathrm{mg} / \mathrm{dL})$ & $116 \pm 35$ \\
$\mathrm{HbA} 1 \mathrm{c}(\%)$ & $8.9 \pm 1.5$ \\
$\mathrm{HOMA}-\mathrm{R}$ & $2.00(1.04-2.96)$ \\
$\mathrm{Ca}(\mathrm{mg} / \mathrm{dL})$ & $9.3 \pm 0.5$ \\
Phosphate $(\mathrm{mg} / \mathrm{dL})$ & $3.9(3.5-4.3)$ \\
Whole PTH $(\mathrm{pg} / \mathrm{mL})$ & $19.2(18.6-19.8)$ \\
$1,25(\mathrm{OH})_{2} \mathrm{D}(\mathrm{pg} / \mathrm{mL})$ & $40.0(28.0-52.0)$ \\
TRACP-5b $(\mathrm{mU} / \mathrm{dL})$ & $343(231-455)$ \\
BAP $(\mu \mathrm{g} / \mathrm{L})$ & $12.7(9.1-16.3)$ \\
Intact OC $(\mathrm{ng} / \mathrm{mL})$ & $3.1(1.8-4.4)$ \\
TrBMD $\left(\mathrm{mg} / \mathrm{cm}{ }^{3}\right)$ & $172 \pm 54$ \\
EMTb $(\mathrm{Gpa})$ & $2.96(2.68-3.24)$ \\
CoTh $(\mathrm{mm})$ & $3.69 \pm 1.28$ \\
VF, $n(\%)$ & $39(22.5)$ \\
\hline
\end{tabular}

Data are expressed as $n, n(\%)$, mean $\pm \mathrm{SD}$, or median (interquartile range) $B M I$ body mass index, $e G F R$ estimated glomerular filtration rate, $F P G$ Fasting plasma glucose, HOMA-R homeostasis model assessment ratio (insulin resistance), IQR interquartile range

difference in the prevalence of VF between men and women. Of interest, the eGFR in the $\mathrm{VF}(+)$ group was $55.0 \pm 20.0 \mathrm{~mL} / \mathrm{min} /$ $1.73 \mathrm{~m}^{2}$, which was significantly lower than that in the $\mathrm{VF}(-)$ group $\left(67.0 \pm 26.1 \mathrm{~mL} / \mathrm{min} / 1.73 \mathrm{~m}^{2}\right)$. Serum BAP, intact OC, whole PTH, and TRACP-5b were significantly higher in the $\mathrm{VF}(+)$ group than in the $\mathrm{VF}(-)$ group. All bone parameters, such as TrBMD, EMTb, and CoTh, were significantly lower in the $\mathrm{VF}(+)$ group.

Comparison of various clinical parameters between T2DM patients with and without VF, after segregation by eGFR $<$ and $\geq 60 \mathrm{~mL} / \mathrm{min} / 1.73 \mathrm{~m}^{2}$

To analyze the effect of excess PTH, which is involved in the stimulation of bone turnover in stage 3 CKD or higher [13, 14], enrolled patients were analyzed separately on the basis of eGFR, $\geq$ and $<60 \mathrm{~mL} / \mathrm{min} / 1.73 \mathrm{~m}^{2}$. PTH was significantly higher with eGFR $<60 \mathrm{~mL} / \mathrm{min} / 1.73 \mathrm{~m}^{2}(23.6[15.8-31.4] \mathrm{pg} / \mathrm{mL}$ vs 17.2 [13.0-21.4]pg/mL for eGFR $\left.\geq 60 \mathrm{~mL} / \mathrm{min} / 1.73 \mathrm{~m}^{2}, p<0.001\right)$.

As shown in Table 3, $105(60.7 \%)$ had eGFR $\geq 60 \mathrm{~mL} / \mathrm{min} /$ $1.73 \mathrm{~m}^{2}$. The $\mathrm{VF}(+)$ group had a significantly lower eGFR $\left(71.0 \pm 8.5 \mathrm{~mL} / \mathrm{min} / 1.73 \mathrm{~m}^{2}\right)$ than the $\mathrm{VF}(-)$ group $(81.9 \pm$ $15.7 \mathrm{~mL} / \mathrm{min} / 1.73 \mathrm{~m}^{2}$ ). Age and duration of T2DM were significantly greater in the $\mathrm{VF}(+)$ group than in the $\mathrm{VF}(-)$
Table 2 Comparison of clinical parameters between T2DM patients with and without VF

\begin{tabular}{llll}
\hline & $\mathrm{VF}(+)(n=39)$ & $\mathrm{VF}(-)(n=134)$ & $p$ value \\
\hline Age (year) & $60.5 \pm 12.3$ & $58.5 \pm 10.0$ & $<0.001^{*}$ \\
Gender (men/women) & $20 / 19$ & $78 / 56$ & 0.467 \\
Duration of T2DM (year) & $19(11-27)$ & $11(3-19)$ & $0.016^{*}$ \\
BMI $\left(\mathrm{kg} / \mathrm{m}^{2}\right)$ & $25.2 \pm 5.3$ & $26.2 \pm 5.5$ & 0.153 \\
Cr $(\mathrm{mg} / \mathrm{dL})$ & $0.86(0.70-1.02)$ & $0.81(0.59-1.03)$ & 0.123 \\
eGFR $\left(\mathrm{mL} / \mathrm{min} / 1.73 \mathrm{~m}^{2}\right)$ & $55.0 \pm 20.0$ & $67.0 \pm 26.1$ & $0.005^{*}$ \\
FPG $(\mathrm{mg} / \mathrm{dL})$ & $117 \pm 37$ & $120 \pm 36$ & 0.499 \\
HbA1c $(\%)$ & $7.7 \pm 1.6$ & $8.4 \pm 1.6$ & $0.045^{*}$ \\
Ca $(\mathrm{mg} / \mathrm{dL})$ & $9.2 \pm 0.6$ & $9.3 \pm 0.5$ & 0.677 \\
Phosphate $(\mathrm{mg} / \mathrm{dL})$ & $3.9(3.6-4.2)$ & $3.8(3.4-4.2)$ & 0.280 \\
BAP $(\mu \mathrm{g} / \mathrm{L})$ & $14.7(10.9-18.5)$ & $12.2(8.8-15.6)$ & $0.035^{*}$ \\
Intact OC $(\mathrm{ng} / \mathrm{mL})$ & $4.3(3.0-5.6)$ & $2.9(1.8-4.0)$ & $0.007^{*}$ \\
$1,25(\mathrm{OH})_{2} \mathrm{D}(\mathrm{pg} / \mathrm{mL})$ & $34.0(22.5-45.5)$ & $41.0(29.0-53.0)$ & 0.775 \\
Whole PTH $(\mathrm{pg} / \mathrm{mL})$ & $20.8(16.2-25.4)$ & $18.2(12.2-24.4)$ & $0.036^{*}$ \\
TRACP-5b (mU/dL) & $427(282-572)$ & $329(219-439)$ & $0.006^{*}$ \\
TrBMD $\left(\mathrm{mg} / \mathrm{cm}{ }^{3}\right)$ & $142 \pm 49$ & $182 \pm 53$ & $<0.001^{*}$ \\
EMTb $(\mathrm{Gpa})$ & $2.72(2.57-2.87)$ & $3.06(2.78-3.34)$ & $<0.001^{*}$ \\
CoTh $(\mathrm{mm})$ & $3.23 \pm 1.07$ & $3.85 \pm 1.31$ & $0.014^{*}$ \\
\hline
\end{tabular}

Data are expressed as mean \pm SD and were analyzed by Student's $t$ test or median (IQR) and were analyzed by Mann-Whitney $U$ test. A $\chi^{2}$ test was used to analyze the difference between men and women

${ }^{*} p<0.05$ (statistical significance)

group. VF prevalence did not differ between men and women. Although TrBMD and CoTh were not lower in the $\mathrm{VF}(+)$ group, EMTb was significantly lower in the $\mathrm{VF}(+)$ group than in the $\mathrm{VF}(-)$ group.

In 68 of the T2DM patients with an eGFR $<60 \mathrm{~mL} /$ $\min / 1.73 \mathrm{~m}^{2}$, VF occurred in as many as $32.4 \%$, significantly higher than the respective value of $16.2 \%$ in those with eGFR $\geq 60 \mathrm{~mL} / \mathrm{min} / 1.73 \mathrm{~m}^{2}$. The $\mathrm{VF}(+)$ group had a significantly higher age and BAP than the $\mathrm{VF}(-)$ group. In addition, serum whole PTH and intact OC tended to be higher in the $\mathrm{VF}(+)$ group. TrBMD, $\mathrm{EMTb}$, and CoTh were significantly reduced in the $\mathrm{VF}(+)$ group compared to the $\mathrm{VF}(-)$ group. Women exhibited higher fracture rate than men but not significantly.

Association between the presence of VF and the bone parameters in T2DM patients

To elucidate factors significantly associated with VF separately in the two patient groups based on eGFR, a multivariate logistic regression analysis was performed. As shown in Table 4 , in patients with an eGFR $\geq 60 \mathrm{~mL} / \mathrm{min} / 1.73 \mathrm{~m}^{2}$, among independent variables including age, gender, duration of T2DM, TrBMD, EMTb, and CoTh, duration of T2DM and 
Table 3 Comparison of clinical parameters of T2DM patients with eGFR $\geq$ and eGFR $<60 \mathrm{~mL} / \mathrm{min}$ between $\mathrm{VF}(+)$ and $\operatorname{VF}(-)$ groups of patients $(n=173)$

\begin{tabular}{|c|c|c|c|c|c|c|}
\hline & \multicolumn{3}{|c|}{$\mathrm{eGFR} \geq 60\left(\mathrm{~mL} / \mathrm{min} / 1.73 \mathrm{~m}^{2}\right)$} & \multicolumn{3}{|c|}{$\mathrm{eGFR}<60\left(\mathrm{~mL} / \mathrm{min} / 1.73 \mathrm{~m}^{2}\right)$} \\
\hline & $\mathrm{VF}(+)(n=17)$ & $\mathrm{VF}(-)(n=88)$ & $p$ value & $\mathrm{VF}(+)(n=22)$ & $\operatorname{VF}(-)(n=46)$ & $p$ value \\
\hline $\mathrm{eGFR}\left(\mathrm{mL} / \mathrm{min} / 1.73 \mathrm{~m}^{2}\right)$ & $71.0 \pm 8.5$ & $81.9 \pm 15.7$ & $0.010^{*}$ & $41.9 \pm 16.6$ & $38.2 \pm 14.7$ & 0.245 \\
\hline Age (year) & $65.5 \pm 12.1$ & $58.0 \pm 12.2$ & $0.035^{*}$ & $71.0 \pm 6.6$ & $65.5 \pm 10.8$ & $0.025^{*}$ \\
\hline Gender (men/women) & $9 / 8$ & $45 / 43$ & 0.891 & $11 / 11$ & $33 / 13$ & 0.079 \\
\hline Duration of T2DM (year) & $21.0(16.7-25.3)$ & $8.0(1.5-14.5)$ & $<0.001 *$ & $18.0(8.5-27.5)$ & $15.0(7.0-23.0)$ & 0.573 \\
\hline HbA1c (\%) & $8.1 \pm 1.6$ & $8.5 \pm 1.7$ & 0.247 & $7.4 \pm 1.5$ & $8.0 \pm 1.5$ & 0.134 \\
\hline $\mathrm{Ca}(\mathrm{mg} / \mathrm{dL})$ & $9.3 \pm 0.4$ & $9.2 \pm 0.4$ & 0.362 & $9.0 \pm 0.8$ & $9.2 \pm 0.6$ & 0.182 \\
\hline Phosphate (mg/dL) & $3.9(3.6-4.2)$ & $3.9(3.5-4.3)$ & 0.766 & $3.8(3.5-4.1)$ & $3.7(3.3-4.1)$ & 0.318 \\
\hline $\mathrm{BAP}(\mu \mathrm{g} / \mathrm{L})$ & $14.6(11.0-18.2)$ & $12.5(8.7-16.3)$ & 0.322 & $16.0(12.1-19.9)$ & $12.0(8.2-15.8)$ & $0.015^{*}$ \\
\hline Intact OC $(\mathrm{ng} / \mathrm{mL})$ & $3.0(0.6-5.4)$ & $2.8(1.8-3.8)$ & 0.350 & $5.3(3.7-6.9)$ & $3.5(1.8-5.2)$ & 0.070 \\
\hline $1,25(\mathrm{OH})_{2} \mathrm{D}(\mathrm{pg} / \mathrm{mL})$ & $42.0(33.2-50.8)$ & $46.0(33.4-58.6)$ & 0.569 & $28.0(39.5-36.5)$ & $29.0(18.5-39.5)$ & 0.700 \\
\hline Whole PTH (pg/mL) & 17.7 (12.8-22.6) & $17.2(13.1-21.3)$ & 0.647 & $24.9(15.1-34.7)$ & $23.7(14.8-32.6)$ & 0.064 \\
\hline TRACP-5b (mU/dL) & $396(238-554)$ & $325(228-422)$ & 0.165 & $456(367-545)$ & $361(223-499)$ & 0.196 \\
\hline $\operatorname{TrBMD}\left(\mathrm{mg} / \mathrm{cm}^{3}\right)$ & $155 \pm 55$ & $177 \pm 52$ & 0.134 & $129 \pm 36$ & $188 \pm 56$ & $<0.001^{*}$ \\
\hline EMTb (Gpa) & $2.66(2.46-2.86)$ & $3.05(2.77-3.33)$ & $0.007^{*}$ & $2.72(2.56-2.88)$ & $3.07(2.78-3.36)$ & $0.004^{*}$ \\
\hline CoTh (mm) & $3.07 \pm 1.16$ & $3.71 \pm 1.21$ & 0.060 & $2.86 \pm 1.10$ & $4.19 \pm 1.32$ & $0.001 *$ \\
\hline
\end{tabular}

Data are expressed as mean \pm SD and were analyzed by Student's $t$ test or median (IQR) and were analyzed by Mann-Whitney $U$ test. $\chi^{2}$ tests were used to analyze the differences between men and women

${ }^{*} p<0.05$ (statistical significance)

EMTb emerged as independent factors significantly associated with VF. In contrast, when the same analysis was performed in those with eGFR $<60 \mathrm{~mL} / \mathrm{min} / 1.73 \mathrm{~m}^{2}$, CoTh was the only independent factor significantly associated with VF.

\section{Discussion}

The present study demonstrated that multivariate regression analysis, including age, gender, duration of T2DM, TrBMD, $\mathrm{EMTb}$, and CoTh as independent variables, longer duration of T2DM and lower EMTb, emerged as independent factors significantly associated with VF in T2DM patients with eGFR $\geq 60 \mathrm{~mL} / \mathrm{min} / 1.73 \mathrm{~m}^{2}$, while CoTh was the only significant factor associated with VF in T2DM patients with eGFR $<60 \mathrm{~mL} / \mathrm{min} / 1.73 \mathrm{~m}^{2}$. This suggests the importance of impaired cortical bone components as the main factor for VF in T2DM patients with stage $3 \mathrm{CKD}$ or higher; this is in contrast with the importance of trabecular bone in T2DM patients with eGFR $\geq 60 \mathrm{~mL} / \mathrm{min} / 1.73 \mathrm{~m}^{2}$.

When comparing clinical parameters between two groups of T2DM patients with and without VF, T2DM VF $(+)$ patients exhibited significantly longer duration of T2DM and significantly lower eGFR than T2DM VF(-) patients (Table 2). Of importance, $\mathrm{T} 2 \mathrm{DM} \mathrm{VF}(+)$ patients had a significantly higher PTH and bone turnover markers, BAP and TRACP-5b, which are not affected by renal dysfunction [27, 28], and significantly lower values of bone parameters, TrBMD, EMTb, and
CoTh, as measured with the new QUS device, than T2DM $\mathrm{VF}(-)$ patients. Serum bone metabolic markers, such as serum BAP and TRACP-5b, were within their respective normal ranges, indicating that bone turnover was at normal levels.

Table 4 Associations between the presence of vertebral fractures and bone parameters in T2DM patients

\begin{tabular}{llll}
\hline & \multicolumn{3}{l}{ Presence of VF } \\
\cline { 2 - 4 } & OR & $95 \% \mathrm{CI}$ & $p$ value \\
\hline Independent variables & & & \\
\hline eGFR $\geq 60 \mathrm{~mL} / \mathrm{min} / 1.73 \mathrm{~m}^{2}$ & 0.99 & $0.92-1.07$ & 0.863 \\
Age (per 1 year increase) & 3.14 & $0.57-17.47$ & 0.190 \\
Gender (women) & 1.11 & $1.04-1.20$ & $0.003^{*}$ \\
Duration of T2DM (per 1 year increase) & 0.31 & $0.09-1.11$ & 0.071 \\
TrBMD (per -1 quartile) & 6.66 & $1.84-24.10$ & $0.004^{*}$ \\
EMTb (per -1 quartile) & 1.84 & $0.64-5.28$ & 0.260 \\
CoTh (per -1 quartile) & & & \\
eGFR $<60$ mL/min/1.73 m ${ }^{2}$ & 1.04 & $0.96-1.13$ & 0.344 \\
Age (per 1 year increase) & 1.41 & $0.27-7.43$ & 0.683 \\
Gender (women) & 0.99 & $0.95-1.06$ & 0.945 \\
Duration of T2DM (per 1 year increase) & 1.37 & $0.31-5.94$ & 0.678 \\
TrBMD (per -1 quartile) & 2.31 & $0.52-10.24$ & 0.272 \\
EMTb (per -1 quartile) & 6.28 & $1.38-28.56$ & $0.050^{*}$ \\
CoTh (per -1 quartile) & &
\end{tabular}

$95 \%$ CI $95 \%$ confidence interval, OR odds ratio

${ }^{*} p<0.05$ (statistical significance) 
Serum intact OC alone was reduced below its normal lower limit, which is characteristic of diabetic osteopathy [29] and might be accounted for by suppression due to poor glycemic control, independent of bone turnover [30].

These findings suggested the prevalence of CKD and the resultant development of secondary hyperparathyroidism with higher bone turnover as a possible mechanism for VF development in $\mathrm{T} 2 \mathrm{DM}$, as $\mathrm{VF}(+)$ patients displayed a significant decline in eGFR along with significant increases in whole PTH and bone metabolic markers. In CKD patients, it is known that serum PTH starts to increase in those with eGFR $<60 \mathrm{~mL} / \mathrm{min} / 1.73 \mathrm{~m}^{2}[13,14]$. We have previously reported that PTH is a major factor causing cortical osteoporosis in hemodialysis (HD) patients; this was accomplished by demonstrating a significant improvement in cortical bone histomorphometric parameters by serial bone biopsy of the iliac crest of patients with refractory secondary hyperparathyroidism before and after parathyroidectomy [31]. There was a strong correlation between serum PTH and BMD at the distal one third of the radius in HD patients [32].

Indeed, several studies have demonstrated that fracture rate at the femur neck, which is enriched in the cortical bone components, was significantly higher in CKD patients with eGFR $<60 \mathrm{~mL} / \mathrm{min} / 1.73 \mathrm{~m}^{2}$ [15-18]. This notion is supported by a report demonstrating that continuous PTH (1-34) injection could cause cortical porosity as well as a reduction of CoTh in dogs [33]. Furthermore, although a variety of mechanisms underlying impaired bone quality in T2DM patients has been proposed [3, 8 , $34,35]$, it has been increasingly recognized that cortical porosity might be a major mechanism explaining the higher fracture rate in T2DM patients $[9,36]$, irrespective of the insignificant reduction in BMD measured by dualenergy X-ray absorptiometry [2-4]. These notions led to a comparison of clinical characteristics of the enrolled patients after dividing them by eGFR $\geq$ or $<60 \mathrm{~mL} / \mathrm{min} /$ $1.73 \mathrm{~m}^{2}$ to examine the effect of hyperparathyroidism on bone metabolism in patients with low eGFR (Table 3). $\mathrm{VF}(+)$ patients with eGFR $\geq 60 \mathrm{~mL} / \mathrm{min} / 1.73 \mathrm{~m}^{2}$ showed significantly lower EMTb and longer duration of T2DM. In contrast, $\mathrm{VF}(+)$ patients with eGFR $<60 \mathrm{~mL} / \mathrm{min} /$ $1.73 \mathrm{~m}^{2}$ showed reduced TrBMD and CoTh. The mechanism by which these bone parameters were significantly lower in $\mathrm{VF}(+)$ patients with eGFR $<60 \mathrm{~mL} / \mathrm{min} / 1.73 \mathrm{~m}^{2}$ might be explained by the occurrence of hyperparathyroidism with the concurrent development of high turnover bone disease.

In addition to duration of T2DM, multivariate regression analysis elucidated EMTb as an independent factor associated with VF in those with eGFR $\geq 60 \mathrm{~mL} / \mathrm{min} /$ $1.73 \mathrm{~m}^{2}$, while CoTh emerged as the only independent factor in those with eGFR $<60 \mathrm{~mL} / \mathrm{min} / 1.73 \mathrm{~m}^{2}$. With lower eGFR, particularly when $<60 \mathrm{~mL} / \mathrm{min} / 1.73 \mathrm{~m}^{2}$, the effect of PTH on bone became greater. Since PTH acts preferentially on cortical bone components, the greater effect of PTH excess in those with eGFR $<60 \mathrm{~mL} / \mathrm{min} / 1.73 \mathrm{~m}^{2}$ might make parameters of cortical bone components, such as CoTh, more important for bone fragility in those with renal dysfunction.

In a study of these groups, we found that the proportion of CKD patients with eGFR $<60 \mathrm{~mL} / \mathrm{min} / 1.73 \mathrm{~m}^{2}$ in a Japanese population was as high as $15 \%$ in their sixties and $27 \%$ in their seventies (data unpublished), which agrees well with the 2012 CKD guide [37]. Due to the development of diabetic nephropathy, it is likely that the prevalence rate of CKD in T2DM patients is much higher [38]. Therefore, the more common occurrence of cortical osteoporosis with DM might be confounded by the coexistence of CKD in T2DM patients.

The mechanism by which CoTh may be associated with VF might have several explanations. First, since PTH enhances bone turnover in trabecular bone as well as cortical bone [39], the reduction of CoTh might reflect bone loss at trabecular bone-enriched vertebral bone. Second, since it was recently recognized that vertebral bone strength is also supported by the cortical bone-enriched vertebral cage [40], a greater deleterious effect of PTH on the cortical cage might cause VF in T2DM patients with eGFR $<60 \mathrm{~mL} / \mathrm{min} / 1.73 \mathrm{~m}^{2}$.

The strength of the present study is that this is the first report suggesting the involvement of diabetic nephropathy in decreased CoTh in DM patients; this was shown by dividing T2DM patients into two groups: those with eGFR $\geq$ or $<60 \mathrm{~mL} / \mathrm{min} / 1.73 \mathrm{~m}^{2}$, the point at which serum PTH is reported to increase $[13,14]$. Therefore, the present study raised the possibility that protection against cortical osteoporosis, which is a definitive risk for femur neck fracture [41], might be obtained by treatment for diabetic nephropathy. Second, the validation of the new QUS device to determine parameters of cortical bone separate from trabecular bone may help distribute this apparatus more widely as a screening tool for cortical osteoporosis without any exposure to X-ray [11], although it is established that HR-pQCT is definitely the most sophisticated apparatus to precisely measure multiple bone parameters, including trabecular and cortical bone components $[42,43]$.

The limitations of the present study are as follows. First, this is a cross-sectional study and is insufficient to disentangle potential relationships among EMTb, CoTh, TrBMD, and the prevalence of VF since all parameters were estimated at a single point. Second, since our study examined a rather small number of Japanese T2DM patents, the results cannot be extended to other ethnicities. A large-scale, multiethnic study is needed to confirm these results. Third, since the T2DM patients had been treated with various drugs for DM, hypertension, and dyslipidemia, some drugs, which might affect bone metabolism, were prescribed. Therefore, the effect of such drugs on bone metabolism may have affected the results. 
In conclusion, this is the first report demonstrating that the bone parameter CoTh is a significant factor independently associated with VF in T2DM patients with eGFR $<60 \mathrm{~mL} / \mathrm{min} / 1.73 \mathrm{~m}^{2}$ but not $\geq 60 \mathrm{~mL} / \mathrm{min} /$ $1.73 \mathrm{~m}^{2}$, thus suggesting the involvement of DM nephropathy in increased serum PTH and the development of bone fragility in T2DM patients.

\begin{abstract}
Acknowledgments We would like to thank Professor Takahiko Otani at the Department of Electrical Engineering, Faculty of Engineering, Doshisha University, Japan, for the help in understanding the bone densitometry LD-100. This work was supported in part of by KAKENHI (Grants-in-Aid for young scientist B; no. 23791041) from Japan Society for the Promotion of Science.
\end{abstract}

\section{Conflicts of interest None.}

Open Access This article is distributed under the terms of the Creative Commons Attribution Noncommercial License which permits any noncommercial use, distribution, and reproduction in any medium, provided the original author(s) and the source are credited.

\section{References}

1. Nicodemus KK, Folsom AR (2001) Iowa Women's Health Study: type 1 and type 2 diabetes and incident hip fractures in postmenopausal women. Diabetes Care 24:1192-1197

2. Schwartz AV, Sellmeyer DE, Ensrud KE, Cauley JA, Tabor HK, Schreiner PJ, Jamal SA, Black DM, Cummings SR (2001) Older women with diabetes have an increased risk of fracture: a prospective study. J Clin Endocrinol Metab 86:32-38

3. Inaba M, Okuno S, Kumeda Y, Yamakawa T, Ishimura E, Nishizawa $Y$ (2005) Increased incidence of vertebral fracture in older female hemodialyzed patients with type 2 diabetes mellitus. Calcif Tissue Int $76: 256-260$

4. Yamamoto M, Yamaguchi T, Yamauchi M, Kaji H, Sugimoto T (2009) Diabetic patients have an increased risk of vertebral fractures independent of BMD or diabetic complications. J Bone Miner Res 24:702-709

5. Vestergaard P (2007) Discrepancies in bone mineral density and fracture risk in patients with type 1 and type 2 diabetes - a metaanalysis. Osteoporos Int 18:427-444

6. Janghorbani M, Van Dam RM, Willett WC, Hu FB (2007) Systematic review of type 1 and type 2 diabetes mellitus and risk of fracture. Am J Epidemiol 166:495-505

7. Nih Consensus Development Panel on Osteoporosis Prevention, Diagnosis Therapy (2001) Osteoporosis prevention, diagnosis, and therapy. JAMA 285:785-795

8. Saito M, Fujii K, Mori Y, Marumo K (2006) Role of collagen enzymatic and glycation induced cross-links as a determinant of bone quality in spontaneously diabetic WBN/Kob rats. Osteoporos Int 17: 1514-1523

9. Burghardt AJ, Issever AS, Schwartz AV, Davis KA, Masharani U, Majumdar S, Link TM (2010) High-resolution peripheral quantitative computed tomographic imaging of cortical and trabecular bone microarchitecture in patients with type 2 diabetes mellitus. J Clin Endocrinol Metab 95:5045-5055
10. Breban S, Padilla F, Fujisawa Y, Mano I, Matsukawa M, Benhamou CL, Otani T, Laugier P, Chappard C (2010) Trabecular and cortical bone separately assessed at radius with a new ultrasound device, in a young adult population with various physical activities. Bone 46: $1620-1625$

11. Yamamoto T, Otani T, Hagino H, Katagiri H, Okano T, Mano I, Teshima R (2009) Measurement of human trabecular bone by novel ultrasonic bone densitometry based on fast and slow waves. Osteoporos Int 20:1215-1224

12. Sai H, Iguchi G, Tobimatsu T, Takahashi K, Otani T, Horii K, Mano I, Nagai I, Iio H, Fujita T, Yoh K, Baba H (2010) Novel ultrasonic bone densitometry based on two longitudinal waves: significant correlation with pQCT measurement values and age-related changes in trabecular bone density, cortical thickness, and elastic modulus of trabecular bone in a normal Japanese population. Osteoporos Int 21:1781-1790

13. Isakova T, Wahl P, Vargas GS, Gutierrez OM, Scialla J, Xie H, Appleby D, Nessel L, Bellovich K, Chen J, Hamm L, Gadegbeku C, Horwitz E, Townsend RR, Anderson CA, Lash JP, Hsu CY, Leonard MB, Wolf M (2011) Fibroblast growth factor 23 is elevated before parathyroid hormone and phosphate in chronic kidney disease. Kidney Int 79:1370-1378

14. Hu MC, Kuro-o M, Moe OW (2012) The emerging role of Klotho in clinical nephrology. Nephrol Dial Transplant 27:2650-2657

15. Nickolas TL, McMahon DJ, Shane E (2006) Relationship between moderate to severe kidney disease and hip fracture in the United States. J Am Soc Nephrol 17:3223-3232

16. Ensrud KE, Lui LY, Taylor BC, Ishani A, Shlipak MG, Stone KL, Cauley JA, Jamal SA, Antoniucci DM, Cummings SR (2007) Renal function and risk of hip and vertebral fractures in older women. Arch Intern Med 167:133-139

17. Fried LF, Biggs ML, Shlipak MG, Seliger S, Kestenbaum B, Stehman-Breen C, Sarnak M, Siscovick D, Harris T, Cauley J, Newman AB, Robbins J (2007) Association of kidney function with incident hip fracture in older adults. J Am Soc Nephrol 18:282-286

18. LaCroix AZ, Lee JS, Wu L, Cauley JA, Shlipak MG, Ott SM, Robbins J, Curb JD, Leboff M, Bauer DC, Jackson RD, Kooperberg CL, Cummings SR (2008) Cystatin-C, renal function, and incidence of hip fracture in postmenopausal women. J Am Geriatr Soc 56:1434-1441

19. Gao P, Schieibei S, D'Amour P, John MR, Rao SD, Schmidt-Gayk H, Cantor TL (2001) Development of a novel immunoradiometric assay exclusively for biologically active whole parathyroid hormone 1-84: implications for improvement of accurate assessment of parathyroid function. J Bone Miner Res 16:605-614

20. Imai E, Horio M, Nitta K, Yamagata K, Iseki K, Tsukamoto Y, Ito S, Makino H, Hishida A, Matsuo S (2007) Modification of the modification of diet in renal disease (MDRD) study equation for Japan. Am J Kidney Dis 50:927-937

21. Tanizawa K, Taniguchi H, Sun X, Ito T, Cao ZB, Sakamoto S, Higuchi M (2014) Common single nucleotide polymorphisms in the FNDC5 gene are associated with glucose metabolism but do not affect serum irisin levels in Japanese men with low fitness levels. Metabolism 63:574-583

22. Otani T (2005) Quantitative estimation of bone density and bone quality using acoustic parameters of cancellous bone for fast and slow waves. Jpn J Appl Phys 44:4578-4582

23. Mano I, Horii K, Takai S, Suzuki T, Nagaoka H, Otani T (2006) Development of novel ultrasonic bone densitometry using acoustic parameters of cancellous bone for fast and slow waves. Jpn J Appl Phys 45:4700-4702

24. Otani T, Mano I, Tsujimoto T, Yamamoto T, Teshima R, Naka H (2009) Estimation of in vivo cancellous bone elasticity. Jpn J Appl Phys 48:07GK05

25. Mano I, Yamamoto T, Hagino H, Teshima R, Takada M, Tsujimoto T, Otani T (2007) Ultrasonic transmission characteristics of in vitro human cancellous bone. Jpn J Appl Phys 46:4858-4861 
26. Genant HK, Wu CY, van Kuijk C, Nevitt MC (1993) Vertebral fracture assessment using a semiquantitative technique. J Bone Miner Res 8:1137-1148

27. Kurajoh $M$, Inaba $M$, Yamada $S$, Imanishi $Y$, Tsuchida $T$, Ishimura E, Nishizawa Y (2008) Association of increased active PTH(1-84) fraction with decreased GFR and serum $\mathrm{Ca}$ in predialysis CRF patients: modulation by serum 25OH-D. Osteoporos Int 19:709-716

28. Yamada S, Inaba M, Kurajoh M, Shidara K, Imanishi Y, Ishimura E, Nishizawa Y (2008) Utility of serum tartrate-resistant acid phosphatase (TRACP5b) as a bone resorption marker in patients with chronic kidney disease: independence from renal dysfunction. Clin Endocrinol (Oxf) 69:189-196

29. Inaba M, Nagasue K, Okuno S, Ueda M, Kumeda Y, Imanishi Y, Shoji T, Ishimura E, Ohta T, Nakatani T, Kim M, Nishizawa Y (2002) Impaired secretion of parathyroid hormone, but not refractoriness of osteoblast, is a major mechanism of low bone turnover in hemodialyzed patients with diabetes mellitus. Am J Kidney Dis 39:1261-1269

30. Inaba M, Nishizawa Y, Mita K, Kumeda Y, Emoto M, Kawagishi T, Nakatsuka K, Shioi A, Morii H (1999) Poor glycemic control impairs the response of biochemical parameters of bone formation and resorption to exogenous 1,25-dihydroxyvitamin D3 in patients with type 2 diabetes. Osteoporos Int 1999(9):525-531

31. Yajima A, Inaba M, Ogawa Y, Tominaga Y, Tanizawa T, Inou T, Otsubo O (2007) Significance of time-course changes of serum bone markers after parathyroidectomy in patients with uraemic hyperparathyroidism. Nephrol Dial Transplant 22:1645-1657

32. Inaba M, Okuno S, Imanishi $Y$, Ueda M, Yamakawa T, Ishimura E, Nishizawa Y (2005) Significance of Bio-intact PTH(1-84) assay in hemodialysis patients. Osteoporos Int 16:517-525

33. Inoue J (1985) Bone changes with long term administration of low dose 1-34 human PTH on adult beagles. Nihon Seikeigeka Gakkai Zasshi 59:409-427

34. Yamamoto M, Yamaguchi T, Yamauchi M, Yano S, Sugimoto T (2008) Serum pentosidine levels are positively associated with the presence of vertebral fractures in postmenopausal women with type 2 diabetes. J Clin Endocrinol Metab 93:1013-1019

35. Okazaki R, Totsuka Y, Hamano K, Ajima M, Miura M, Hirota Y, Hata K, Fukumoto S, Matsumoto T (1997) Metabolic improvement of poorly controlled noninsulin-dependent diabetes mellitus decreases bone turnover. J Clin Endocrinol Metab 82:2915-2920

36. Patsch JM, Burghardt AJ, Yap SP, Baum T, Schwartz AV, Joseph GB, Link TM (2013) Increased cortical porosity in type 2 diabetic postmenopausal women with fragility fractures. J Bone Miner Res 28:313-324

37. Japan nephrology society (2012) Clinical Practice Guidebook for Diagnosis and Treatment of Chronic Kidney Disease. Nihon Jinzo Gakkai Shi 54: 1034-1191

38. Luk AO, Ma RC, So WY, Yang XL, Kong AP, Ozaki R, Ko GT, Chow CC, Cockram CS, Chan JC, Tong PC (2008) The NCEPATPIII but not the IDF criteria for the metabolic syndrome identify type 2 diabetic patients at increased risk of chronic kidney disease. Diabet Med 25:1419-1425

39. Yajima A, Inaba M, Tominaga Y, Ito A (2007) Minimodeling reduces the rate of cortical bone loss in patients with secondary hyperparathyroidism. Am J Kidney Dis 49:440-451

40. Jamal SA, Gilbert J, Gordon C, Bauer DC (2006) Cortical pQCT measures are associated with fractures in dialysis patients. $\mathrm{J}$ Bone Miner Res 21:543-548

41. Bell KL, Loveridge N, Power J, Garrahan N, Meggitt BF, Reeve J (1999) Regional differences in cortical porosity in the fractured femoral neck. Bone 24:57-64

42. Nishiyama KK, Macdonald HM, Buie HR, Hanley DA, Boyd SK (2010) Postmenopausal women with osteopenia have higher cortical porosity and thinner cortices at the distal radius and tibia than women with normal aBMD: an in vivo HR-pQCT study. J Bone Miner Res $25: 882-890$

43. Zebaze RM, Ghasem-Zadeh A, Bohte A, Iuliano-Burns S, Mirams M, Price RI, Mackie EJ, Seeman E (2010) Intracortical remodelling and porosity in the distal radius and post-mortem femurs of women: a cross-sectional study. Lancet 375:1729-1736 